\title{
Industrial Management Flexibility in Times of Economic Change
}

\author{
by Friedrich Thomée
}

The forum has set itself an immense task in asking the speakers to deal in 45 minutes with problems which are so vital that they can really only be treated exhaustively and with the necessary care in long discussions and seminars. However, I shall attempt to comment on this fundamental theme of entrepreneurial activity from the viewpoint of industry.

From the composition of the audience I see that it consists predominantly of representatives of institutions responsible for security and from among the ranks of insurers. I shall attempt to make clear to these gentlemen too the situation of manufacturing industry in its micro and macro economic aspects.

If we proceed from the task before us today, then we shall recognize clearly two poles in the subject. Around the first pole is centred the problem of enterprise management in its essential functions from the setting of objectives to decision making and control, the second pole concerns risk as a consequence of the uncertainty which comes from the continuous changing of given or expected economic conditions. The constant changing of sets of data naturally forces entrepreneurs, whose task it is to combine factors of production in the attainment of an economic objective, continually to change decisions. This constant change, ladies and gentlemen, is the essential element in business management. The entrepreneur lives in the certainty that he must reckon with uncertainty, which may be the source of risk, the cause of losses, may trigger off crises or even the closure of the business. He cannot, however, base his behaviour on this negative sequence, otherwise he would take no risks at all. Rather, at the beginning of each deliberation he sees the opportunity. He desires to profit from a mastery of uncertainty, works in the expectation of a profit and strives in the end to attain dominance in his sector. This is the sequence of objectives which the entrepreneur must pursue in order to maintain his very existence. In so doing, he must constantly endeavour to become and to remain better than the competitor, for if he should come to the conclusion that he is worse, he would have to give up the path which he had taken, i.e. his strategy.

In order to explain the subject of the forum, namely risk in enterprise, I should first like to describe briefly the object under consideration, namely the "enterprise". In this context I like to use the formulation of the cybernetics specialists, according to whom the enterprise is a complex of overlapping systems. The task of the entrepreneur consists in analyzing these systems as well as precisely mastering their structure and function, once the components, i.e. the elements of this system, are classified, weighted and grouped. The British cybernetics specialist, Stafford Beer, distinguishes two impor- 
tant component groups. The first can be predicted with certainty - he calls it the determinated group - the other, the probabilistic group, is on the other hand indefinite and cannot be forecast with certainty at the initial stage of planning. With this analysis the cybernetics specialists have in fact drawn together the essential elements of the entrepreneurial system, of which they go on to say that it is an input/output system consisting of interdependent subsystems which are especially subject to change, uncertainty and risk. And finally, according to the cybernetics specialists, as all measures also take place within time, these subsystems are additionally burdened with the increased risk of time lags, i.e. all the interdependencies do not react on schedule.

As a rule the entrepreneur makes permanent changes to the type and amount of factors employed. By means of investment - and also disinvestment! - e.g. the level of output is shifted, a process which the Americans describe as a "break through". This naturally costs money and the return on it is burdened with all kinds of uncertainty until the full redemption of the capital invested.

These processes are so important because they determine the direction of entrepreneurial activities over a long period, and therefore also determine risk and opportunity. And even if the entrepreneur changes nothing he has a significant function to carry out, namely the controlling function, the comparison of target with actual figures, with the constant readiness to adapt should deviation from the planned course occur.

Both functions intersect constantly and subsume all other activities in the entrepreneurs' sphere of operations.

During the course of business in an enterprise basically " normal " and "abnormal " movements must be ascertained. By normal movements is commonly understood the action and reaction in processes which may well be determined by the economic trend. - Recession too is in my opinion a perfectly normal development. - Abnormal developments indicate shifts in the trend of a structural nature. We are here dealing with a complete change of the set of data and a departure from the relative state of equilibrium between the resources employed and the yield achieved. When the entrepreneur becomes involved in a change of trend of this kind, which is generally determined by outside factors, then he must use a different set of strategic tools from those used to deal with movements within the economic cycle. Above all, he needs a different degree and a different kind of flexibility. And in most cases, when crises have occurred within enterprises it has been clearly seen that changes of trend were realized too late and were therefore tackled with unsuitable tools.

If we now consider in detail the functions of the entrepreneur which he exercises in the system described, then we see that in the knowledge of his resource potential he sets targets, plans, decides, controls and adjusts. The gravest errors of entrepreneurial activity almost always occur in the beginning of a project or concept to be developed - depending on its size and importance - when the potential must be estimated and the objectives set. I would even maintain that many entrepreneurs reflect not at all or too little on their portfolio and their objectives and, furthermore, only rarely formulate them in the necessary way. When taking stock of potential, products must be judged according to their growth prospects and their relative shares of the market. In the interest of developing realistic targets, the positions of the competitors in the market sectors concerned must likewise be analyzed. Only then can the type, the 
extent and the time projection for the operational and strategic targets be established. It is too superficial and in addition very risky if entrepreneurs during boom periods for example lay overriding emphasis on maximization of profits, while during periods of recession they base their behaviour rather on the preservation of jobs. Whatever target level is set, it is important that it should be clear at the beginning of the strategic decision, that its feasibility should be tested and that it should be fed into the information system in a clearly formulated manner.

I should now like to touch upon a few elements of planning. We commonly distinguish strategic and operational planning. These must be both logically justifiable in themselves and coordinated, to avoid conflicts of objective. If for example the Volkswagen corporation formulated a strategic plan to conquer the market of the South American continent, then this strategic concept would have to be clear to all operational units involved in the task, including and particularly those who had operationally to pursue other subsidiary targets. Head Office could, for example, employ the potential of the Brazilian subsidiary to provide funds for other temporarily less profitable markets. Even such a conflict of targets as this would have to be carefully planned, convincingly justified and clearly shown in the information system. Otherwise the enterprise would move into a phase of uncertainty which in certain circumstances could even lead to symptoms of crisis.

Regarding the aspect of " risk" with which we are concerned here in this forum, the period is a particularly important planning criterion. If, for example, one wishes to judge the financial significance of the USA project of the Volkswagen Company, then one must be clear that for a few years in the investment period profits must be sacrified which would initially have been achieved had exports remained unchanged, even under the adverse conditions of a low dollar rate. In the expectation of a higher yield sustained over a long period, however, losses are consciously accepted in the interim during a start-up phase.

Such plans, which are long-term in their setting of targets, must always take into account the suspected plans of the competitors. This obviously gives rise to additional risks through false estimations of their behaviour.

This close competitor orientation is necessary because every entrepreneur must attempt to fight his way from the marginal position to a dominant position. This does not mean, however, that the Volkswagen Company, for example, wanted to dominate General Motors. What it does, however, mean is that the Volkswagen Company is making every effort to find a sector of the motor industry in which it is stronger than all its competitors. If it is clear at the outset that this could not happen, then trading in a specific market and with a specific product should cease. For it is inevitable, that the marginal suppliers must always be in a crisis-prone situation, since whenever the sets of data in the overall economic cycle change they are only hovering around the break-even line and are always exposed to the risk of losses, while the dominant competitors always have high cash flow reserves at their disposal so that they can more easily overcome periods of recession or even crises with accumulated reserves. It is therefore my opinion that an entrepreneur must always strive, for the sake of reducing the level of uncertainty, to achieve dominance. This naturally presupposes that he knows his own strengths and weaknesses and those of his competitors in terms of 
products and markets. Both are of great importance. Those were a few basic reflections on the execution of planning as an element in the preparatory process towards decision making.

Decision making, then, is the clearly visible expression of entrepreneurial activity, in practice its principal function. In the process of arriving at his decision the entrepreneur must select the optimum alternatives most likely to minimize the risk. In the decision making phase the entrepreneur stands completely alone, as all the auxiliary tools of a highly sophisticated management have previously been employed with the aim of enabling a selection of the optimum alternatives to be made. The decision arrived at in many cases determines for long periods the direction of activities, through which the enterprise achieves the planned success or, on the other hand, makes losses.

After the making of the decision comes the adjustment phase. Adjustment is the daily realignment of sets of data which deviate from the plan. Adjustment incorporates replanning, reorientation and new decisions. In this controlling phase all the economic auxiliary tools of the entrepreneur come fully into play. They give him a daily indication of where deviations from the plan force him to investigate into their causes and to give a critical account for the deviation, and then cause him to reorientate himself. As long as there is no departure from the general trend, this adjustment is in my opinion the principal task of the managerial level below the board of a company.

If the entrepreneur has mastered his task and has made professional use of all the tools of management to set objectives, to plan and to make decisions which he constantly adjusts, then the risk is reduced as far as is humanly possible, but is not eliminated. Flexibility can never be replaced by planning. I should like, therefore, in the short time offered here, to examine that complex of problems which encompasses the essential area of data through which crises are unleashed or prevented, the portfolio. The fundamental causes for losses which are recognizable later usually lie in a wrong assessment of potential. There are - as you know - entrepreneurs who, though they have high-flying plans, overestimate their possibilities; there are also those who, though they have appropriate possibilities at their disposal, yet do not arrange them correctly according to their weight and significance. Therefore, the most important factor in all deliberations is the knowledge of one's own potential resources in relation to those of the competition.

The degree of flexibility of potential depends essentially on the following groups of factors :

\section{The restriction of location}

The location or locations of an enterprise determine its degree of manoeuvrability. Old locations offer the enterprise all the advantages of integration into the existing infrastructure, new ones, on the other hand, offer the possibility of reorientation towards changed and more favourable determining factors. The level of material, personnel and financial dependence determines the degree of mobility and therefore the economic success of an enterprise. Decisions concerning the fixing of locations contain considerable entrepreneurial risks since they can be corrected only with great difficulty. 
When selecting a location not only the geographical conditions are of interest, but above all the economic, cultural and political, that is to say the socio-political infrastructure also. Only when the infrastructure as an integrated whole has been analyzed, assessed and weighted, can such decisions of location be made as, for example, whether to erect a works in America, Yugoslavia, Nigeria or in Iran.

If one considers the factor labour alone, then this factor implies the whole managerial behaviour pattern towards politics in all its aspects, and towards all the institutions which represent labour. It is concerned both with the techniques of labour deployment and with working morale. In this context I should like to make just a few points : it is, for example, not the same thing whether one considers employment costs in America, in Japan or in the Federal Republic of Germany in one's calculation. Even where the hourly wage rates are the same labour efficiency varies greatly. When one considers the average period of absence of the workers then, for example, in America in the motor industry 226 days a year are worked, in Germany on average 196 days and in Japan in companies with a four shift day 320 days. Thus we see that this factor alone, together with the varying tendency towards strikes and the general technical and economic productivity, has a considerable bearing on the determination of location. The extent to which the flexibility of management is restricted is also evident. One should always examine whether, and under what conditions, the level of employment can be adapted to fluctuating demand.

Closely connected with the location are also the type and the extent of the capital input. But here also, even if all the instruments of investment calculation have been used and the results in terms of yield and liquidity have been calculated precisely in advance, changes in external circumstances - e.g. exchange rates - can reduce the plan to absurdity at a stroke. I shall give one example: before the devaluation of the dollar the Volkswagen cost approximately DM 6000 , which was then equivalent to approximately $\$ 1500$. Two and a half years later costs and prices had risen by approximately $25 \%$. Instead of DM 6000 the car now cost DM 7600 . With dollar rate of $1: 2.50$, however, the American importer had to pay approximately $\$ 3000$ for the car. For the American customer the price of the car had therefore more than doubled. An investigation and reorientation of the whole concept of the company was thus unavoidable. The Volkswagen Company decided to shift production of the Rabbit (volume seller) to the USA in order to produce and to sell under the same conditions as the competition. An investment of this type naturally involves considerable risks and requires the input of unusually large funds. Since a "normal situation" built up over decades is being structurally altered, then particularly in the initial period considerable financial burdens must be reckoned with, which must be added to the capital expenditure. It is perfectly correct to argue that such investments make the corporation as a whole more flexible in the long run. The entrepreneurial risk - which is the subject of our discussions today - lies in relinquishing financial flexibility and fixing resources in favour of an improved sales flexibility in the long term with the prospect of an increase in partial and ultimately in overall returns. Here the inner, though only short-term, conflict between liquidity and profitability becomes clear. At this point I should like to give a brief indication of the problems which can arise from tying liquidity and profitability to foreign currencies in investments abroad by referring to the devaluation of the Mexican Peso. The devaluation of the Peso by 
about $80 \%$ against the US dollar burdened investments financed in foreign currency to such an extent that many banks and enterprises were involved in considerable difficulties, which are forcing them to carry out a thorough reexamination of their investment and financing planning. I can only indicate here the risks that beset foreign activities today.

\section{The product range and the market position}

The product range and the market position are among the especially clearly recognizable components of the potential of an enterprise which $I$ have presented here. The flexibility of these factors depends essentially on their substitutability, on the significance of one part for the whole as well as on their classification in growth categories and relative market shares. It is quite obvious that a product with high growth prospects and a still relatively low share of the market is at the beginning of its development potential, and is therefore worthy of investment, while a product with low growth prospects and a relatively low share of the market is virtually a candidate for withdrawal from the market. In all the conceivable phases and combinations of growth and market share the entrepreneur must so arrange his decisions - taking into account the competition also - that he maintains the necessary flexibility to be able to react optimally during the course of the planned life or the unexpectedly shorter or longer life of a product. The fact that such flexibility too generally involves very high costs (e.g. for new products developed in stock) once again throws light on the risk of committing funds.

Owing to the market transparency of the motor industry this development can be especially clearly seen. The "Beetle" of the Volkswagen Company e.g. in the postwar period met with a worldwide receptive market for small, relatively simply constructed and easy-to-service vehicles. The growth prospects were considerable and by means of massive investment - measured by the standards of the day - they resulted in shares of the market being captured. With the reorientation of the customers' ideas towards greater comfort - in order to sketch a very complex situation briefly and simply - new growth areas emerged in that sector of the market. In its cycle of development the "Beetle" moved first into a position where it continued to have a high share of the market but low growth prospects until, in the final phase, even the relatively high share of the market was lost. Nowadays, in the highly industrialized countries the "Beetle" is sold in practice only to enthusiasts, while in countries with the attitudes of Europe during the fifties it is still in great demand. The Volkswagen Company therefore had to replace the Beetle with a new product generation with high growth prospects such as the Golf, which is now at the beginning of its life cycle. These remarks were intended to show the risks involved in a commitment of potential and how the ups and downs of an enterprise depend upon the flexibility of the management in the execution of all its functions.

In conclusion I should like to mention that there are of course innumerable other risk factors with which the entrepreneur is daily confronted. To describe them would certainly go far beyond the scope of my remarks. However, I trust you will allow me to refer to the multitude of state interventions and institutional impediments ; measures which force the entrepreneur constantly to adapt, in order to avoid risks and losses. 
In this connection I must stress that in the final analysis not only this or that enterprise is subject to risk with its possible negative consequences, but all who participate directly or indirectly in the enterprise. For the risk extends to - and this list implies no order of priority - banks, insurance companies, the shareholders, the employees and the public; it affects the suppliers and the trade, indeed through taxes even the state and under certain circumstances even several states. This correlation between the risk of enterprise and the body politic is, in my opinion, a part of the theme of this forum. And the significance of the problem can only be estimated if one knows what a lasting influence enterprises in their entirety or in the form of an individual company can have on the course of economic events and furthermore on the framework of political decisions. 